\title{
Joint Determination of Preventive Maintenance and Buffer Stock for a Production Unit under Lease
}

\author{
Thanawath Niyamosoth iD, Supachai Pathumnakul iD \\ Khon Kaen University (Thailand) \\ thanani@kkku.ac.th,supa_pat@kkku.ac.th
}

Received: January 2018

Accepted: June 2018

\begin{abstract}
:
Purpose: The purpose of this work is to develop a mathematical model for simultaneously determining the optimal period of preventive maintenance actions and the optimal size of buffer stock for a production unit that is owned by a lessor and leased to a lessee under a lease contract.

Design/methodology/approach: A mathematical model is formulated and a numerical procedure is developed for finding the optimal period of preventive maintenance actions and the optimal size of buffer stock to minimize the total expected costs considering both a lessor and a lessee over a lease period.

Findings: The proposed model gives better solutions than those where the maintenance cost to the lessor and the production inventory cost to the lessee are minimized separately.

Originality/value: The joint determination of preventive maintenance and safety stock is a topic that has been extensively studied for decades. The majority of the models reported in the literature implicitly assume that the firm owns the production unit and maintenance actions are done in-house. However, equipment acquisition through leasing is a common practice nowadays. Normally, under a lease contract, the lessor who owns the equipment is responsible for maintenance services. This may lead to a conflict between the lessor and the lessee concerning the optimal choice of maintenance actions. To solve this conflict, we propose a joint determination of preventive maintenance and safety stock model for a production unit under a lease. The objective of our model is to simultaneously determine the optimal period of preventive maintenance actions that the lessor needs to perform and the optimal size of buffer stock the lessee needs to produce so that the total combined expected costs to both parties over the lease period are minimized.
\end{abstract}

Keywords: production, inventory, preventive maintenance, safety stock, buffer stock, leased equipment, lease contract

\section{Introduction}

Reliability issues play an important role in designing and analyzing production inventory systems nowadays. The importance of these issues stems from the fact that every production unit has a degree of unreliability and will fail at some time during production. Normally, interruptions due to breakdowns incur shortage costs and corrective maintenance costs to the firm. To reduce those costs, the firm can either produce excess safety stocks to buffer against demands during breakdowns or carry out preventive maintenance (PM) to reduce the likelihood of failures. Formerly, these two strategies for coping with breakdowns were separately studied as reported in the literature. An early unified model was proposed by Cheung and Hausman (1997). In that work, the authors 
investigated the trade-offs between the two strategies and provided optimality conditions for which either one or both strategies should be implemented to minimize the cost function. Dohi, Okamura and Osaki (2001) modified the model of Cheung and Hausman (1997) by correcting some assumptions in that work. They proposed a new model to determine the optimal times to carry out PM actions and the optimal safety stock level that minimize the expected cost per unit time at steady-state. Chelbi and Ait-Kadi (2004) studied an unreliable production unit that continuously supplies input to a subsequent assembly line. They proposed a mathematical model for finding the optimal periodic preventive maintenance policy and buffer stock strategy. The objective of the model was to minimize the total expected cost per unit time and ensure the continuity of supplies to the subsequent assembly line. Chelbi and Rezg (2006) considered a production system similar to that of Chelbi and Ait-Kadi (2004). They proposed a joint determination model to simultaneously determine the optimal duration after which a PM action must be performed and the optimal buffer stock level given that a required long-term availability level that must be satisfied. For simplicity, most models in the literature traditionally assume some restrictive assumptions, such as not allowing breakdowns when building up the buffer stock. By relaxing the restrictive assumptions, Gharbi, Kenne and Beit (2007) developed a more realistic joint preventive maintenance and safety stock model where breakdowns can occur at any time. Li and Zuo (2007) developed a joint optimization of maintenance and inventory model to determine the number of major failures that would warrant a replacement of the system and the level of safety stock where the total expected production inventory and maintenance cost rate during the system's lifetime are minimized. Numerical results obtained by Monte Carlo simulation showed that the joint model gives better solutions than those where maintenance and inventory control were optimized separately. Murino, Romano and Zoppoli (2009) studied an unreliable production system that was maintained using a Condition Based Maintenance (CMB) policy. The purpose of their work was to determine, by simulation, various potential maintenance interventions, based on the concept of thresholds, and the optimal size of the buffer so that the global system costs are minimized. Chakraborty and Giri (2012) proposed a joint determination of an optimal safety stock and preventive maintenance model for an unreliable and imperfect production system, where the production facility not only fails from time to time, but also produces defective items when it shifts to the out-of-control state. Gan, Zhang, Zhou and Shi (2015) proposed a model that simultaneously optimized maintenance, buffer stock, and spare parts for an unreliable production system consisting of two serial machines. The purpose of the model was to determine the optimal strategies for preventive maintenance, buffer stock, and spare parts that minimize the long-term expected costs. Cheng, Zhou and $\mathrm{Li}$ (2015) studied a production system in which an unreliable upstream machine, subject to random failures and imperfect preventive maintenance, supplies input to a downstream machine. A buffer stock is built between the two machines to prevent interruptions to production due to failures and preventive maintenance. The objective of the study was to determine the optimal size of the buffer stock and the working age of the upstream machine to initiate preventive maintenance so that the average cost rate is minimized. Zhou and Liu (2016) applied the theory of constraints (TOC) to the joint preventive maintenance and buffer stock problem with the consideration of quality loss due to system deterioration. The objective of the proposed model was to find the optimal PM schedule and buffer size that minimize the average operating costs, consisting of PM costs, $\mathrm{CM}$ costs, holding costs, and quality loss, over the planning period. The author concluded that the proposed TOC-based model was superior to the separate maintenance strategy in terms of lower costs and higher output. Nahas (2017) developed a joint determination of buffer stock and preventive maintenance model for a serial production line consisting of $\mathrm{n}$ unreliable machines with $\mathrm{n}-1$ buffer stocking points. The objective of the proposed model was to determine the optimal buffer allocation and the optimal PM policy that minimize the total system costs subject to the desired throughput and limit on the total buffer capacity.

Most of the joint determination of preventive maintenance and safety stock models in the literature are implicitly based on the assumption that the firm owns the production unit and that maintenance actions, both corrective maintenance $(\mathrm{CM})$ and preventive maintenance $(\mathrm{PM})$, are done in-house. However, nowadays businesses have several options for acquiring the production facilities. Equipment acquisition through leasing has become a popular option for several reasons, including rapid technological obsolescence, the high cost of ownership (Nisbet \& Ward, 2001), convenience and flexibility, increased cash flow, tax benefits, and opportunity to transfer upgrade costs to the lessor (Kelly, Khayum \& Price, 2013). According to the Equipment Leasing and Finance Foundation (ELFF), in 
2015, 68\% (\$1.02 trillion) of the investment in equipment and software in the US was financed through leases, loans, and lines of credit. Of that $68 \%, 39 \%$ was in the form of lease (Equipment Leasing \& Finance Foundation, 2016). Equipment leasing brings about several new issues to both the lessor and the lessee. One of those issues is about maintenance service. When leasing equipment, the lessor, who is the owner of the equipment, is responsible for maintenance actions, both CM and PM, with no additional charges to the lessee, who is the user of the equipment, according to the lease contract. Maintenance actions are no longer an issue for the lessee, but for the lessor (Jaturonnatee, Murthy \& Boondiskulchok, 2006).

Often, the lease contract will specify the conditions for maintenance services, both CM and PM, that the lessor must perform over the lease period. Additionally, the lease contract often specifies penalty charges for the lessor if the leased equipment fails too frequently or repairs are not completed within a reasonable time. Normally, PM actions can reduce CM and penalty costs. However, performing PM actions more often than necessary incurs excessive PM cost. Therefore, in determining the terms of the lease, the lessor needs to determine an optimal maintenance policy that makes an appropriate trade-off between CM and PM costs. Optimal preventive maintenance models for leased equipment have been presented in detail by numerous researchers. A few examples include Jaturonnatee et al. (2006), Pongpech and Murthy (2006), Pongpech, Murthy and Boondiskulchock (2006), Niyamosoth and Pongpech (2007), Murthy and Pongpech (2008), Boonyathap and Jaturonnatee (2010), Zhou, Li, Xi and Lee (2015), Ben Mabrouk, Chelbi and Radhoui (2016a,b, 2017).

Niyamosoth (2014) developed a mathematical model for determining the optimal buffer stock for an unreliable production facility undergoing corrective and periodic preventive maintenance based on the work of Chelbi and Ait-Kadi (2004). Unlike previous studies that assumed that maintenance actions were done in-house, the authors studied a case of equipment leasing where a production unit owned by the lessor, who also provided maintenance services, was leased to the lessee under a contract. Provided that the optimal maintenance policy was prescribed by the lessor, the objective of the model was to find the optimal size of buffer stock the lessee needs to produce at the beginning of each production cycle ensuring a continuous supply to a subsequent assembly line and the total expected cost for the lessee over the lease period is minimized. The author observed that determining optimal maintenance policy for the lessor and optimal buffer stocks for lessee separately may lead to a conflict between the two parties because the optimal choice of maintenance policy for the lessor may not fit to the optimal production inventory strategy of the lessee.

As a result, to solve the conflict between the lessor and the lessee as discussed by Niyamosoth (2014), in this paper we propose a joint determination of preventive maintenance and buffer stock model for a production unit under lease. Our objective was to simultaneously determine the optimal period of preventive maintenance actions the lessor needs to perform and the optimal size of buffer stock the lessee needs to produce at the beginning of each production cycle to ensure a continuous supply to a subsequent assembly line. This is done so that the total expected costs to both parties over the lease period are minimized.

The remainder of this paper is organized as follows: in Section 2, we define the underlying concepts of the model, state the model's assumptions, and specify the notation used in the model. In Section 3, a mathematical model is formulated expressing the total expected costs over the lease period. In Section 4, a simple numerical procedure employed for finding the optimal solutions is presented. The fifth section is dedicated to the numerical experimentation and the sensitivity analysis. Finally, the conclusions of our work together with a brief discussion of our future research is provided in Section 6.

\section{Concepts, Assumptions and Notation}

The proposed model is based on the following concepts, assumptions, and notation.

\subsection{Concepts and Assumptions}

In this work, we consider an unreliable production unit that is owned by a lessor and leased to a lessee under a lease contract for a period of length, L. According to the lease contract, the lessor is responsible for maintenance, both $\mathrm{CM}$ and PM, throughout the lease period with no additional costs to the lessee. We assume that both CM and PM are done with random durations. We also assume that $\mathrm{CM}$ actions are minimal repairs. Each $\mathrm{CM}$ action brings the 
production unit back to the working state, but the failure intensity function after each repair remains unchanged from the pre-failure state (Barlow \& Hunter, 1960). Additionally, PM actions are done periodically by the lessor at times $j T, j=1,2, \ldots, k$ over the lease period. We assume that PM actions are perfect maintenance. In this case, each PM action restores the operating condition of the production unit to its original new condition, i.e., after each PM action, the production unit has its initial failure intensity function restored (Pham \& Wang, 1996). Both CM and PM actions result in maintenance costs to the lessor. The costs of $\mathrm{CM}$ actions involve all resources required for unplanned remedial actions purposed to restore a system from a failed to a working state. Alternatively, the costs of PM actions involve the costs of planned actions intended to either reduce the likelihood of failures or to improve the reliability of the system (Blischke $\&$ Murthy, 2000). In our work, we assume that the $j^{\text {th }}$ PM action performed by the lessor reduces the likelihood of failure by reducing the failure intensity function by $\delta_{j}, j=1,2, \ldots, k$, where $k$ is the number of PM actions done over the lease period. However, in the case that CM actions are minimal and PM actions are perfect, we have $\delta_{1}=\delta_{2}=\ldots=\delta_{k}=\lambda_{0}(T)$, where $\lambda_{0}(T)$ is the failure intensity with no PM actions at time, $T$ (see Figure 1). Additionally, in this work, we assume that the lease contract also specifies two types of penalties, Penalty-1 and Penalty-2, to the lessor. The lessor incurs Penalty-1 if he cannot restore the production unit from failed state to working state within the repair time limit, $\tau$. The lessor incurs Penalty- 2 whenever a failure occurs during the lease period. Practically, PM actions can reduce both CM and penalty costs. However, performing PM actions more often than necessary can result in excessive PM costs. This implies that the lessor needs to determine the optimal PM actions through an appropriate trade-off between PM costs and costs resulting from failures. In addition to the maintenance and penalty costs incurred by the lessor, the system total cost in our work also includes the operating cost of the lessee. The lessee's operating cost in our work consists of the inventory holding cost and the shortage cost. In order to ensure the continuity of supply to a subsequent assembly line at a constant rate $\alpha$ during repair or preventive maintenance, a buffer stock of size $S$ is rapidly built up at a rate $\omega$ at the beginning of each production cycle. This results in inventory holding cost to the lessee. At the beginning of each production cycle, the production unit produces at a total rate $\omega+\alpha$ until the buffer stock of size $S$ is fully accumulated. The size of the buffer stock must be large enough to cover at least the average demands during CM periods within a time interval of length $T$. At the instant $j T, j=1,2, \ldots, k$ the production unit has to be paused for a period of time to perform PM actions. During this period, a sufficient buffer stock must remain to prevent the subsequent assembly line from stoppage. If the time to carry out a PM action is longer than the time needed to use up the remaining buffer stock in PM period, shortage occurs, resulting in shortage costs to the lessee. In this work, we assume shortage costs are charged on a per unit basis.

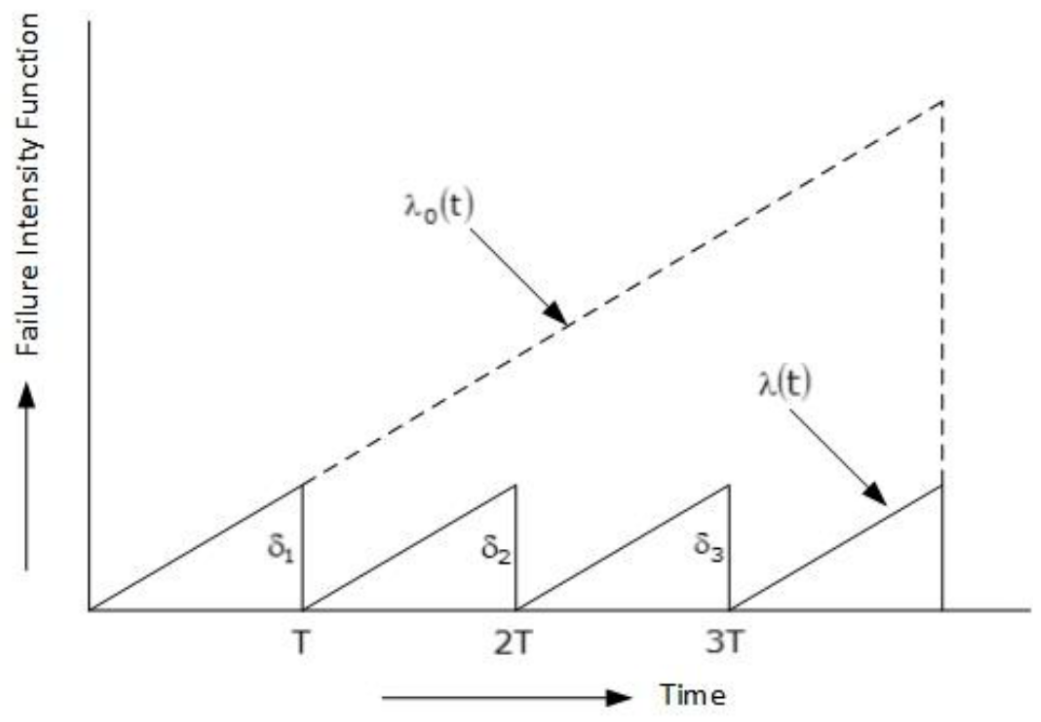

Figure 1. Plot of a Failure Intensity Function 


\subsection{Notation}

- $F(t)$ : Failure distribution function.

- $f(t)$ : Failure density function associated with $F(t)$.

- $\quad \lambda_{0}(t)$ : Failure intensity function without PM actions.

- $\lambda(t)$ : Failure intensity function with PM actions.

- $\Lambda_{0}(t)$ : Cumulative failure intensity function without PM actions $\left[=\int_{0}^{t} \lambda_{0}(x) d x\right]$.

- $\Lambda(t)$ : Cumulative failure intensity function with PM actions $\left[=\int_{0}^{t} \lambda(x) d x\right]$.

- $N(t)$ : Number of failures over $[0, t)$.

- $Y$ : Repair time.

- $G(y)$ : Repair-time distribution function.

- $g(y)$ : Repair-time density function $\left[=\frac{d G(y)}{d y}\right]$.

- T: Scheduled period to carry out PM actions.

- $Z$ : Time required to perform a PM action.

- $\quad b(z):$ Probability density function associated with $Z$.

- $C_{f}$ : Average $\mathrm{CM}$ cost per failure.

- a: Fixed PM cost.

- $\quad b$ : Variable PM cost.

- $\delta_{j}$ : Reduction in failure intensity function due to the $j^{\text {th }} \mathrm{PM}$ action.

- $\tau$ : Repair time limit.

- $C_{t}$ : Penalty cost per unit time if the repair time takes longer than $\tau$ [Penalty-1].

- $C_{n}$ : Penalty cost per failure [Penalty-2].

- $\quad$ : Buffer stock size.

- $\quad b$ : Holding cost per unit per unit time.

- $\omega, \alpha:$ production rates.

- $\pi$ : Shortage cost per unit short.

\section{Model Formulation}

In this section, we develop a mathematical model to simultaneously determine the optimal preventive maintenance period, $\mathrm{T}$, and the optimal buffer stock size, $\mathrm{S}$, that minimize the total expected costs, considering both the lessor and the lessee, over the lease period. The maintenance policy for the lessor is similar to that proposed by Pongpech and Murthy (2006) except that in our work every PM action is assumed to be perfect. Also, the underlining production system of the lessee is based on the work of Chelbi and Ait-Kadi (2004), where a buffer stock of size $S$ was built up at the beginning of the production cycle to ensure the continuity of supply to a subsequent assembly line. 


\subsection{Expected Cycle Costs to the Lessor}

In this work, the production unit owned by the lessor is leased to the lessee for a period of $L$. During the lease period, the lessor performs PM actions with a period of $T$, incurring PM costs to the lessor. For simplicity, we assume that PM actions are perfect. Additionally, failures occurring within the PM period $T$ are rectified by making minimal repairs incurring CM costs to the lessor. Moreover, the lessor also incurs two types of penalties, Penalty-1 and Penalty-2. Penalty-1 occurs if the repair time exceeds a time limit $\tau$. Penalty- 2 is imposed whenever a failure occurs during the lease period. Thus, the cycle costs incurred by the lessor consist of 1) CM costs, 2) PM costs, 3) Penalty- 1 costs, and 4) Penalty- 2 costs. The details for each cost are given as follows:

\section{1) CM Costs}

Let $N(t)$ denote the number of failures over $[0, t)$. The expected number of failures over $[0, T)$ is given by Jaturonnatee et al. (2006) as:

$$
E[N(T)]=\Lambda_{0}(T)=\int_{0}^{T} \lambda_{0}(t) d t,
$$

where $\lambda_{0}(t)$ is the failure intensity function without PM actions.

Assuming that average $\mathrm{CM}$ cost is $C_{f}$ per failure, the expected $\mathrm{CM}$ cost in a cycle is given by:

$$
E\left[T C_{f}\right]=C_{f} \Lambda_{0}(T)
$$

\section{2) PM Costs}

We assume that each PM action incurred both fixed and variable costs, which depended on $\delta_{j}$, the reduction in failure intensity function due to $j^{\text {th }} \mathrm{PM}$ action. Therefore, the cost of $j^{\text {th }} \mathrm{PM}$ action is given by $C_{p}\left(\delta_{j}\right)=a+b \delta_{j}$, $j=1,2, \ldots k$, where $a>0$ is the fixed cost and $b \geq 0$ is the variable cost (Jaturonnatee et al., 2006). However, in the case that $\mathrm{CM}$ actions involve minimal repairs and $\mathrm{PM}$ actions are perfect maintenance, we have $\delta_{1}=\delta_{2}=\ldots=\delta_{k}=\lambda_{0}(T)$. Thus, the cost of a PM action in a cycle is given by:

$$
C_{p}(T)=a+b \lambda_{0}(T)
$$

\section{3) Penalty-1 Costs}

For each failure occurring within the PM period, $T$, if the repair time $Y$ is longer than the repair time limit $\tau$, the lessor incurs Penalty-1. Let $C_{t}$ be the penalty cost per unit time if the repair is not completed within $\tau$ and $\varphi_{1}$ be the Pentalty- 1 cost in a cycle. Then, the expected Penalty- 1 cost in a cycle is given by:

$$
E\left[\varphi_{1}\right]=C_{t} \Lambda_{0}(T) \int_{\tau}^{\infty}(y-\tau) g(y) d y
$$

where $g(y)$ is the repair-time density function.

Using integration by parts, we can rewrite (4) as the following:

$$
E\left[\varphi_{1}\right]=C_{t} \Lambda_{0}(T) \int_{\tau}^{\infty}(1-G(y)) d y
$$

where $G(y)$ is the repair-time distribution function.

\section{4) Penalty-2 Costs}

During the PM period, $T$, the lessor incurs Penalty- 2 whenever a failure occurs, regardless of the repair time. $C_{n}$ is the penalty cost per failure and $\varphi_{2}$ is the Penalty- 2 cost in a cycle. Then, the expected Penalty- 2 cost in a cycle is given by: 


$$
E\left[\varphi_{2}\right]=C_{n} \Lambda_{0}(T)
$$

Combining all these costs, we obtain the expected cycle cost to the lessor given by:

$$
E\left[C C_{L}(T)\right]=C_{f} \Lambda_{0}(T)+a+b \lambda_{0}(T)+C_{t} \Lambda_{0}(T) \int_{\tau}^{\infty}(y-\tau) g(y) d y+C_{n} \Lambda_{0}(T) .
$$

\subsection{Expected Cycle Cost to the Lessee}

At the beginning of each PM cycle, the production unit produces at a rate $\omega+\alpha$, rapidly building up a buffer stock of size $S$ at a rate $\omega$, incurring inventory holding costs and fulfilling the demand of the subsequent assembly line at a rate $\alpha$. A shortage occurs in case that the time to carry out a PM action is longer than the time needed to use up the remaining buffer stock in the PM period, incurring shortage costs. Thus, the cycle cost to the lessor consists of 1) inventory holding costs, and 2) shortage costs. The details for each cost are given as follows:

\section{1) Inventory Holding Costs}

The evolution of the buffer stock in our work is based on that proposed by Chelbi and Ait-Kadi (2004) as in Figure 2 .

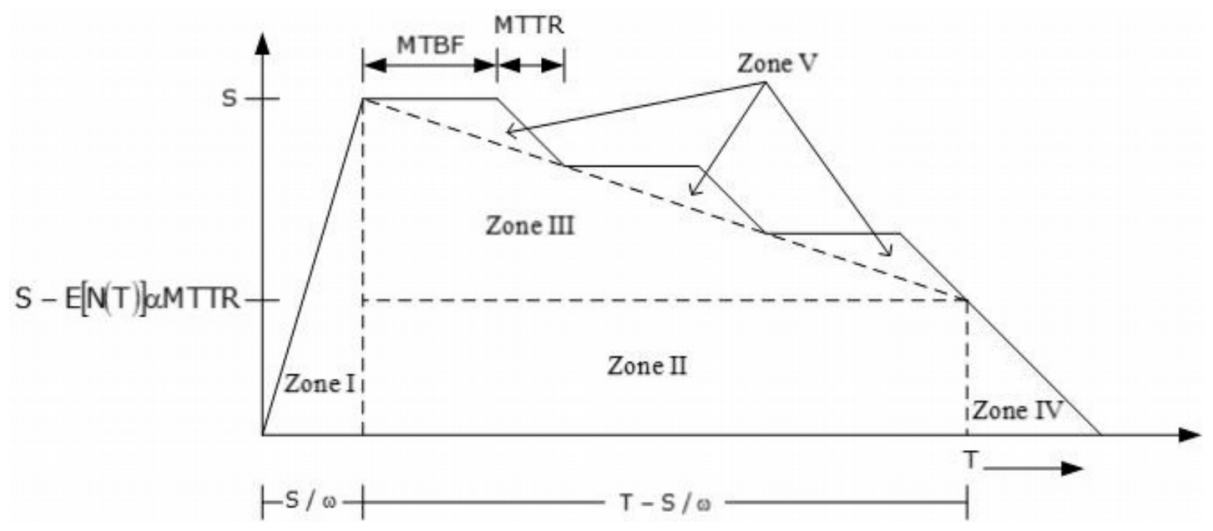

Figure 2. Evolution of the buffer stock.

At the beginning of each PM cycle, a buffer stock of size $S$ is rapidly built up at a rate $\omega$. This buffer stock is used to guard against the demands of the subsequent assembly line during $\mathrm{CM}$ and $\mathrm{PM}$ actions. Assuming that $\mathrm{CM}$ actions are minimal repairs, the mean time between failures $(M T B F)$ in the interval $(0, T)$ is given by Ebeling (2010):

$$
M T B F=\frac{T}{E[N(T)]}=\frac{T}{\Lambda_{0}(T)}
$$

Failures occurring during the PM cycle are rectified through CM actions with the mean time to repair (MTTR) is given by:

$$
\operatorname{MTTR}=E[Y]=\int_{0}^{\infty} y g(y) d y=\int_{0}^{\infty}(1-G(y)) d y
$$

Given that the demand rate of the subsequent assembly line is $\alpha$, the buffer stock decreases at a rate $\alpha$ during the $\mathrm{CM}$ period. As a result, the remaining buffer stock, $R$, at a point in time to carry out a PM action, $T$, is given by:

$$
R=S-E[N(T)] \alpha M T T R .
$$


Letting h be the inventory holding cost per unit per unit time and IHC denote the inventory holding cost per cycle, the expected inventory holding costs in a cycle can be expressed as follows:

$$
\begin{aligned}
E[I H C]= & \frac{h S^{2}}{2 \omega}+h(S-E[N(T)] \alpha M T T R)(T-S / \omega)+\frac{h}{2}(T-S / \omega) E[N(T)] \alpha M T T R \\
& +\frac{h(S-E[N(T)] \alpha M T T R)^{2}}{2 \alpha}+\frac{h m(S / \omega, T) \alpha M T T R \cdot M T B F}{2}
\end{aligned}
$$

Where $m(S / \omega, T)=E[N(T)-N(S / \omega)]=\int_{S / \omega}^{T} \lambda_{0}(t) d t$ is the expected number of failures in the interval $(S / \omega, T)$ (Ebeling, 2010).

\section{2) Shortage Costs}

Shortage costs are possibly incurred if the time required to perform a PM action, $Z$, exceeds the time to use up the remaining buffer stock $R$. In this work, we assume that shortage costs are charged on a per unit basis. If the time spent on a PM action is $Z$, the number of shortages per cycle $\eta(z, R)$ will be:

$$
\eta(z, R)=\left\{\begin{array}{l}
0 \quad \text { if } z<R / \alpha, \\
\alpha(z-R / \alpha) \text { if } z \geq R / \alpha .
\end{array}\right.
$$

Thus, the expected number of shortages per cycle is given by:

$$
E[\eta(z, R)]=\int_{R / \alpha}^{\infty}(z-R / \alpha) h(z) d z
$$

where $h(z)$ is the probability density function associated with PM duration.

Letting $\pi$ be the shortage cost per unit short and SC denote the shortage cost in a cycle, the expected shortage cost in a cycle is given by:

$$
E[S C]=\pi \alpha \int_{R / \alpha}^{\infty}(z-R / \alpha) h(z) d z
$$

Combining all these costs, we obtain the expected cycle cost to the lessee as:

$$
\begin{aligned}
E\left[C C_{l}(T, S)\right]= & \frac{h S^{2}}{2 \omega}+h(S-E[N(T)] \alpha M T T R)(T-S / \omega) \\
& +\frac{h}{2}(T-S / \omega) E[N(T)] \alpha M T T R+\frac{h(S-E[N(T)] \alpha M T T R)^{2}}{2 \alpha} \\
& +\frac{h m(S / \omega, T) \alpha M T T R \cdot M T B F}{2}+\pi \alpha \int_{R / \alpha}^{\infty}(z-R / \alpha) h(z) d z .
\end{aligned}
$$

\subsection{Total Expected Costs per Cycle}

The total expected costs incurred in a cycle is the sum of the expected cycle cost to the lessor $E\left[C C_{L}(T)\right]$ and the expected cycle cost to the lessee $E\left[C C_{l}(T, S)\right]$. Combining these two costs yields the total expected cost per cycle given by: 


$$
\begin{aligned}
E[T C C(T, S)]=C_{f} \Lambda_{0}(T)+a+b \lambda_{0}(T)+C_{t} \Lambda_{0}(T) \int_{\tau}^{\infty}(y-\tau) g(y) d y+C_{n} \Lambda_{0}(T) \\
+\frac{h S^{2}}{2 \omega}+h(S-E[N(T)] \alpha M T T R)(T-S / \omega) \\
+\frac{h}{2}(T-S / \omega) E[N(T)] \alpha M T T R+\frac{h(S-E[N(T)] \alpha M T T R)^{2}}{2 \alpha} \\
+\frac{h m(S / \omega, T) \alpha M T T R \cdot M T B F}{2}+\pi \alpha \int_{R / \alpha}^{\infty}(z-R / \alpha) h(z) d z .
\end{aligned}
$$

\subsection{Expected Cycle Length}

As can be seen in Figure 2, the expected cycle length is equal to $T$ plus the expected duration to carry out a PM action. Letting $C L$ denote length of the cycle, the expected cycle length is given by:

$$
E[C L]=T+E[Z]=T+\int_{0}^{\infty} z h(z) d z
$$

\subsection{Expected Number of Cycles Over the Lease Period}

The expected number of cycles over the lease period can be obtained by dividing the length of the lease period, $L$, by the expected cycle length $E[C L]$. Letting $N C(L)$ denote the number of cycles over the lease period, $L$, the expected number of cycles over the lease period is given by:

$$
E[N C(L)]=\frac{L}{E[C L]}
$$

\subsection{Total Expected Cost Over the Lease Period}

The objective function of our model is the total expected costs over the lease period. This is obtained by multiplying $E[T C C(T, S)]$ by $E[N C(L)]$ and is given as follows:

$$
E[T C(T, S)]=E[N C(L)] E[T C C(T, S)] .
$$

substituting $\frac{L}{E[C L]}$ for $E[N C(L)]$, we can rewrite $E[T C(T, S)]$ as the following:

$$
E[T C(T, S)]=\frac{L \cdot E[T C C(T, S)]}{E[C L]} .
$$

Note that in case that we consider the lessor and the lessee separately, the total expected costs for the lessor, $E\left[T C_{L}(T)\right]$, and the total expected costs for the lessee, $E\left[T C_{l}(T, S)\right]$, over the lease period are given as:

$$
E\left[T C_{L}(T)\right]=\frac{L \cdot E\left[C C_{L}(T)\right]}{E[C L]},
$$

and,

$$
E\left[T C_{l}(T, S)\right]=\frac{L \cdot E\left[C C_{l}(T, S)\right]}{E[C L]},
$$


Summing these yields:

$$
E\left[T C_{L}(T)\right]+E\left[T C_{l}(T, S)\right]=E[T C(T, S)]
$$

\subsection{The Constraints on $S$ and $T$}

From Chelbi and Ait-Kadi (2004), it is assumed that the time required to produce a buffer stock of size $S$ is very short compared to the PM period, T, i.e., $S / \omega<<$ T. Furthermore, a buffer stock of size $S$ must be large enough to cover at least the average demands during the $\mathrm{CM}$ periods within the time interval of length, T, i.e., $S \geq E[N(T)]$ MTTR $\alpha$. Thus, the constraint on the size of the buffer stock $S$ is given by:

$$
E[N(T)] M T T R \alpha \leq S<\omega T,
$$

where the constraint on the PM period, $T$, is simply $0<T<L$.

\subsection{Mathematical Model}

Finally, we attain the mathematical model for the proposed problem as follows:

$$
\text { Minimize } Z=E[T C(T, S)] \text {. }
$$

$$
\text { Subject to: } E[N(T)] M T T R \alpha \leq S<\omega T \text { and } 0<T<L \text {. }
$$

\section{Numerical Procedure}

In this section, a simple iterative numerical procedure for finding the optimal solutions $T^{*}$ and $S^{*}$ of the proposed model is provided. The details are given as follows:

Step 1. Select an initial value of $T$, denoted by $T_{i}$, in the interval $(0, L)$. This value should be close to zero.

Step 2. Find $S_{i}^{*}=$ Minimize $E\left[T C\left(T_{i}, S\right)\right]$, subject to: $E\left[N\left(T_{i}\right)\right] M T T R \alpha \leq S<\omega T_{i}$. This is a nonlinear optimization problem of one variable, which can easily be solved using any of several available software packages.

Step 3. Store $E\left[T C\left(T_{i}, S_{i}^{*}\right)\right]$.

Step 4. Let $T_{i}=T_{i}+\Delta T$, where $\Delta T$ is the step size.

Step 5. If $T_{i}<L$, go to Step 2. Otherwise, stop, since the optimal solution has been attained. $E\left[T C^{*}\left(T^{*}, S^{*}\right)\right]=\min \left\{E\left[T C\left(T_{i}, S_{i}^{*}\right)\right]\right\}$, for $i=0$ to $L-T_{0} / \Delta T$ where $T_{0}$ is the initial value of $T$.

\section{Numerical Results and Sensitivity Analysis}

In this section, the numerical results and the sensitivity analysis of the proposed model are provided. The details are given as follows:

\subsection{The Input Data}

Failure distribution: Weibull distribution with the corresponding intensity function is given by:

$$
\lambda_{0}(t)=\frac{\beta}{\theta}\left(\frac{t}{\theta}\right)^{\beta-1}, \quad \theta>0, \beta>0, t \geq 0
$$


Where $\theta$ is the scale parameter and $\beta$ is the shape parameter. For simplicity, we assume that $\beta=2$, indicating a linearly increasing failure rate (Ebeling, 2010). Note that for a Weibull distribution, the mean time to failure $(M T T F)$ is found from $M T T F=\theta \Gamma\left(1+\frac{1}{\beta}\right)$ (Ebeling, 2010). Therefore, in our work we assume that $\theta=0.5642$ so that the mean time to failure $(M T T F)$ is approximately 0.5 months.

- Repair-time distribution: An exponential distribution with the cumulative distribution function (CDF) given by:

$$
G(y)=1-e^{-\mu y}, \quad \mu>0, y \geq 0
$$

Where $\mu$ is the constant repair rate, and the corresponding probability density function (PDF) is given by:

$$
g(y)=\mu e^{-\mu y}, \quad \mu>0, y \geq 0
$$

Note that in this case, the MTTR in Equation (9) is simply equal to $\frac{1}{\mu}$. Therefore, in our work we assume that $\mu=200$ so that $M T T R=0.005$ months.

- Preventive maintenance duration distribution: This is an exponential distribution with the corresponding PDF given by:

$$
h(z)=\gamma e^{-\gamma z}, \quad \gamma>0, z \geq 0,
$$

where $\gamma$ is the constant rate of performing PM actions.

Note that in this case $E[Z]$ in Equation (17) is simply equal to $\frac{1}{\gamma}$. Therefore, in our work we assume that $\gamma=25$ so that $E[Z]=0.04$ months.

- $\quad L=5$ years, $C_{f}=2,500 \$, a=100 \$, b=50 \$, C_{t}=300 \$, C_{n}=200 \$, \tau=0.005$ month.

- $\quad h=1 \$ /$ unit/month, $\omega=7,200$ units/month, $\alpha=28,800$ units/month, $\pi=2 \$ /$ unit.

\subsection{The Numerical Results}

Table 1 shows optimal solutions of the proposed model and of the two separated models. Each separated model considers either the lessor or the lessee, but not both.

According to the results shown in Table 1, an optimal policy that minimizes the total expected costs, considering both the lessor and the lessee, over the lease period consists of carrying out periodic PM actions with $T^{*}=0.3$ months and building a buffer stock of $S^{*}=2,160$ units. In doing so, the total expected costs over the lease period will be $\$ 304,552$. Note that this policy is neither an optimal strategy for the lessor nor the lessee. It is actually a strategy in which the two parties compromise, so that the total expected costs, considering both the lessor and the lessee, over the lease period are minimized. In the cases where the lessor and the lessee are considered separately, the optimal solutions for the lessor and for the lessee are $T^{*}=0.1$ month, $S^{*}=720$ units and $T^{*}=1.4$ months, $S^{*}=1,398.69$ units respectively. In both cases, the total expected costs over the lease period are higher than that of the proposed model, $\$ 642,529$ and $\$ 834,846$ respectively. Hence, we can conclude that the proposed model gives a better solution than the separated models. It can be observed from the numerical data that for given values of $T$, the optimal size of buffer stock, $S^{*}$, of the proposed model and of the separated model considering only the lessee are always equal. This is because $E[T C(T, S)]=E\left[T C_{L}(T)\right]+E\left[T C_{l}(T, S)\right]$. Therefore, when $T$ is given, $E[T C(T, S)]$ is merely $E\left[T C_{l}(T, S)\right]$ plus a constant, i.e., $E\left[T C_{L}(T)\right]$. This constant does not affect the choice of $S^{*}$. 


\begin{tabular}{|c|c|c|c|c|c|c|c|}
\hline \multicolumn{3}{|c|}{$\begin{array}{l}\text { Optimal solutions } \\
\text { of the proposed model considering } \\
\text { both the lessor and the lessee }\end{array}$} & \multicolumn{2}{|c|}{$\begin{array}{l}\text { Optimal solutions } \\
\text { of the separated model } \\
\text { considering only the lessor }\end{array}$} & \multicolumn{3}{|c|}{$\begin{array}{l}\text { Optimal solutions } \\
\text { of the separated model } \\
\text { considering only the lessee }\end{array}$} \\
\hline$T$ (months) & $S^{*}$ & $E\left[T C\left(T, S^{*}\right)\right]$ & $T$ (months) & $E\left[T C_{L}(T)\right]$ & $T$ (months) & $S^{*}$ & $E\left[T C_{l}\left(T, S^{*}\right)\right]$ \\
\hline 0.1 & 720 & 642,529 & 0.1 & $92,679.4$ & 0.1 & 720 & $549,849.6$ \\
\hline 0.2 & 1,440 & 337,959 & 0.2 & 125,545 & 0.2 & 1,440 & $212,414.0$ \\
\hline 0.3 & 2,160 & 304,552 & 0.3 & 169,020 & 0.3 & 2,160 & $135,532.0$ \\
\hline 0.4 & 2,880 & 340,540 & 0.4 & 215,871 & 0.4 & 2,880 & $124,669.0$ \\
\hline 0.5 & $2,758.36$ & 398,935 & 0.5 & 264,223 & 0.5 & $2,758.36$ & $134,712.0$ \\
\hline 0.6 & $2,076.96$ & 449,821 & 0.6 & 313,371 & 0.6 & $2,076.96$ & $136,450.0$ \\
\hline 0.7 & $1,758.46$ & 497,404 & 0.7 & 362,994 & 0.7 & $1,758.46$ & $134,410.0$ \\
\hline 0.8 & $1,607.52$ & 544,364 & 0.8 & 412,921 & 0.8 & $1,607.52$ & $131,443.0$ \\
\hline 0.9 & $1,492.23$ & 591,476 & 0.9 & 463,056 & 0.9 & $1,492.23$ & $128,420.0$ \\
\hline 1.0 & $1,419.4$ & 639,024 & 1.0 & 513,339 & 1.0 & $1,419.4$ & $125,685.0$ \\
\hline 1.1 & $1,378.7$ & 687,117 & 1.1 & 563,730 & 1.1 & $1,378.7$ & $123,387.0$ \\
\hline 1.2 & $1,364.07$ & 735,787 & 1.2 & 614,203 & 1.2 & $1,364.07$ & $121,584.0$ \\
\hline 1.3 & $1,371.62$ & 785,034 & 1.3 & 664,741 & 1.3 & $1,371.62$ & $120,293.0$ \\
\hline 1.4 & $1,398.69$ & 834,846 & 1.4 & 715,923 & 1.4 & $1,398.69$ & $118,923.0$ \\
\hline 1.5 & $1,443.37$ & 885,205 & 1.5 & 765,958 & 1.5 & $1,443.37$ & $119,247.0$ \\
\hline 1.6 & $1,504.24$ & 936,090 & 1.6 & 816,621 & 1.6 & $1,504.24$ & $119,469.0$ \\
\hline 1.7 & $1,580.22$ & 987,480 & 1.7 & 867,310 & 1.7 & $1,580.22$ & $120,170.0$ \\
\hline 1.8 & $1,670.45$ & $1,039,360$ & 1.8 & 918,023 & 1.8 & $1,670.45$ & $121,337.0$ \\
\hline 1.9 & $1,774.26$ & $1,091,710$ & 1.9 & 968,756 & 1.9 & $1,774.26$ & $122,954.0$ \\
\hline 2.0 & $1,891.1$ & $1,144,510$ & 2.0 & $1,019,510$ & 2.0 & $1,891.1$ & $125,000.0$ \\
\hline
\end{tabular}

Table 1. Optimal solutions of the proposed model

\subsection{Sensitivity Analysis}

One can perform sensitivity analyses on various model parameters to see their impact on the optimal solutions. Two critical parameters are the average $\mathrm{CM}$ cost per failure, $C_{f}$, and the shortage cost per unit short, $\pi$. We expect that as $C_{f}$ increases, $T^{*}$ should decrease. This is because the lessor tends to perform PM actions more often when $\mathrm{CM}$ cost is expensive. We also expect that as $\pi$ increases, $T^{*}$ should increase. This is because, when $\pi$ is high, performing PM actions too often can result in excessive shortage costs to the lessee. The results are given in Tables 2 and 3 respectively.

According to the results shown in Table 2, we can see that as $C_{f}$ increases, $T^{*}$ decreases as to be expected. This means that the lessor tends to carry out PM actions more often when the average CM cost per failure is high. The results shown in Table 3 also confirms our expectation. We can see that as $\pi$ increases, $T^{*}$ increases as to be expected. This means that when the shortage cost per unit short is high, it is inappropriate to perform PM actions too often. Doing so can lead to excessive shortage costs to the lessee. Another observation we obtain from Table 3 is the effect of $\pi$ on $S^{*}$. We can see that as $\pi$ increases, $S^{*}$ also increases. This observation is not beyond our expectation. Pragmatically, when the shortage cost per unit short is high, the lessee should carry large amount of buffer stocks to guard against possible shortages during PM periods. The effects of $C_{f}$ and $\pi$ on the optimal solutions can be shown in Figures 3, 4, and 5 respectively. 


\begin{tabular}{|r|r|r|r|}
\hline \multicolumn{1}{|c|}{$C_{f}$} & $T^{*}$ & \multicolumn{1}{|c|}{$S^{*}$} & $E\left[T C\left(T^{*}, S^{*}\right)\right]$ \\
\hline 100 & 0.4 & 2,880 & 176,041 \\
\hline 500 & 0.4 & 2,880 & 203,456 \\
\hline 1000 & 0.3 & 2,160 & 229,711 \\
\hline 2,500 & 0.3 & 2,160 & 304,552 \\
\hline 5,000 & 0.2 & 1,440 & 416,496 \\
\hline
\end{tabular}

Table 2. The effect of $C_{f}$ on the optimal solutions

\begin{tabular}{|r|r|r|r|}
\hline$\pi$ & $T^{*}$ & \multicolumn{1}{|c|}{$S^{*}$} & $E\left[T C\left(T^{*}, S^{*}\right)\right]$ \\
\hline 1 & 0.2 & 1,440 & 254,140 \\
\hline 2 & 0.3 & 2,160 & 304,552 \\
\hline 5 & 0.4 & 2,880 & 381,733 \\
\hline 10 & 0.5 & 3,600 & 449,717 \\
\hline 15 & 0.5 & 3,600 & 480,737 \\
\hline
\end{tabular}

Table 3. The effect of $\pi$ on the optimal solutions

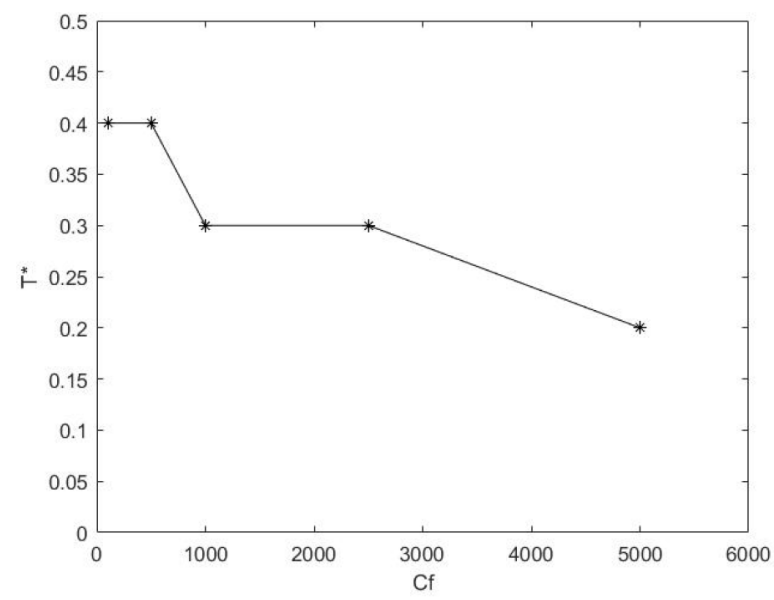

Figure 3. The effect of $C_{f}$ on $T^{*}$

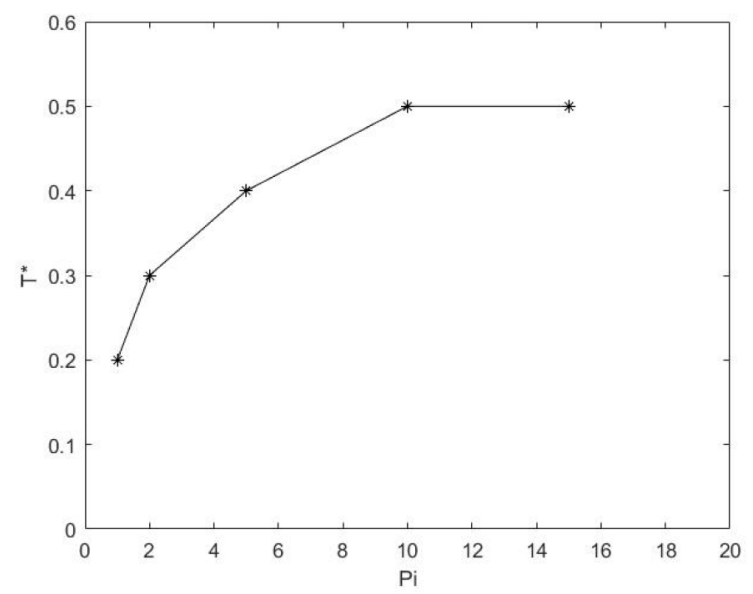

Figure 4. The effect of $\pi$ on $T^{*}$ 


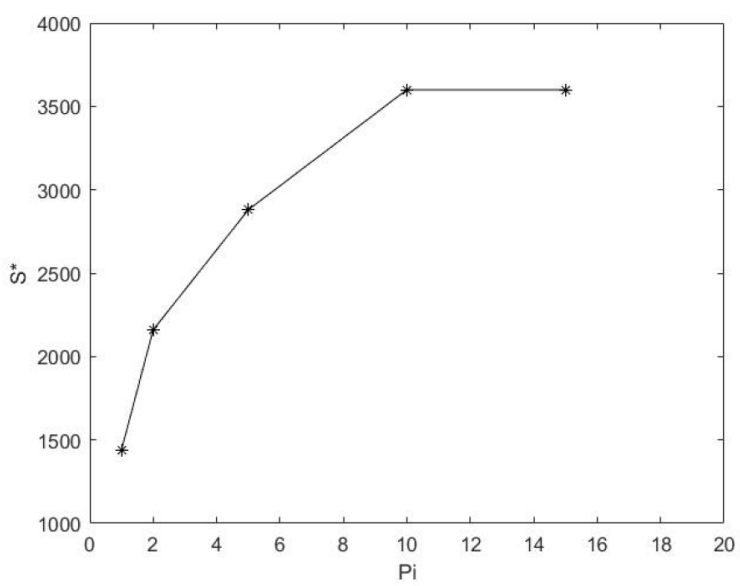

Figure 5. The effect of $\pi$ on $S^{*}$

\section{Conclusions}

This paper proposes a periodic preventive maintenance policy and safety stock strategy for an unreliable production unit being leased. Under a lease contract, both corrective maintenance and preventive maintenance are done by the lessor. The lessee needs to build a buffer stock of size $S$ at the beginning of each PM cycle to ensure the continuity of supply to a subsequent assembly line during CM and PM periods. The purpose of the proposed model is to simultaneously determine the optimal PM period, $T$, and the size of a buffer stock, $S$, that minimize the total combined expected costs of the lessor and the lessee over a lease period. The numerical results show that the proposed model gives a better solution than the separated models considering either the lessor or the lessee. Hence, we can conclude that when determining the optimal policy for a PM period, $T$, and the size of a buffer stock, $S$, for a production unit under lease, both costs related to the lessor and costs related to the lessee should be taken into account. This may help the two parties solve conflicts which possibly occur when the optimal strategy of each party is separately determined.

Finally, the problem presented in this paper can be extended in several ways. These include the cases where PM actions are imperfect and where the leased production unit is previously used rather than a new unit. These two extensions are both considerations in our ongoing research. Furthermore, as each the lessor and the lessee will seek minimizing its own costs, not the overall costs, the problem proposed in this paper is possibly considered as an example of Game theory problems. The investigation for this extension is opened for future research.

\section{Declaration of Conflicting Interests}

The authors declared that there are no potential conflicts of interest with respect to the research, authorship, and/or publication of this article.

\section{Funding}

This work was financially supported by the Young Researcher Development Project of Khon Kaen University.

\section{References}

Barlow, R.E., \& Hunter, L.. (1960). Optimal preventive maintenance policy. Operations Research, 8(1), 90-100. https://doi.org/10.1287/opre.8.1.90

Ben Mabrouk, A., Chelbi, A., \& Radhoui, M. (2016a). Optimal imperfect preventive maintenance policy for equipment leased during successive periods. International Journal of Production Research, 54(17), 5095-5110. https://doi.org/10.1080/00207543.2016.1146417

Ben Mabrouk, A., Chelbi, A., \& Radhoui, M. (2016b). Optimal imperfect preventive maintenance strategy for leased equipment. International Journal of Production Economics, 178, 57-64. https://doi.org/10.1016/j.ijpe.2016.04.024 
Ben Mabrouk, A., Chelbi, A., \& Radhoui, M. (2017). Optimal hybrid imperfect preventive maintenance policy for leased equipment. IFAC-PapersOnLine, 50(1), 13698-13703. https://doi.org/10.1016/j.ifacol.2017.08.2542

Blischke, W.R., \& Murthy, D.N.P. (2000). Reliability modeling, prediction, and optimization. New York: John Wiley \& Sons. https://doi.org/10.1002/9781118150481

Boonyathap, P., \& Jaturonnatee, J. (2010). Multiple periodic preventive maintenance for used equipment under lease. Proceedings of The International MultiConference of Engineers and Computer Scientists 2010 (IMECS 2010). Hong Kong. Available at: http://www.iaeng.org/publication/IMECS2010/IMECS2010 pp1852-1857.pdf (Accessed: January 2018).

Chakraborty, T., \& Giri, B.C. (2012). Joint determination of optimal safety stocks and production policy for an imperfect production system. Applied Mathematical Modeling, 36(2), 712-722.

https://doi.org/10.1016/j.apm.2011.07.012

Chelbi, A., \& Ait-Kadi, D. (2004). Analysis of a production/inventory system with randomly failing production unit submitted to regular preventive maintenance. European Journal of Operational Research, 156(3), 712-718.

https://doi.org/10.1016/S0377-2217(03)00254-6

Chelbi, A., \& Rezg, N. (2006). Analysis of a production/inventory system with randomly failing production unit subjected to a minimum required availability level. International Journal of Production Economics, 99(1-2), 131-143. https://doi.org/10.1016/j.ijpe.2004.12.012

Cheng, G.-Q., Zhou, B.-H., \& Li, L. (2015). Joint optimisation of buffer size and preventive maintenance for a deteriorating upstream machine. International Journal of Systems Science: Operations \& Logistics, 2(4), 199-210. https://doi.org/10.1080/23302674.2015.1018366

Cheung, K.L., \& Hausman, W.H. (1997). Joint determination of preventive maintenance and safety stocks in an unreliable production environment. Naval Research Logistics, 44(3), 257-272. https://doi.org/10.1002/(SICI)15206750(199704)44:3<257::AID-NAV2>3.0.CO;2-7

Dohi, T., Okamura, H., \& Osaki, S. (2001). Optimal control of preventive maintenance schedule and safety stocks in an unreliable manufacturing environment. International Journals of Production Economics, 74(1-3), 147-155.

https://doi.org/10.1016/S0925-5273(01)00121-9

Ebeling, C.E. (2010). An introduction to reliability and maintainability engineering second edition. Illinois: Waveland Press.

Equipment Leasing \& Finance Foundation (2016). U.S. equipment finance market study: 2016-2017. Available at: https://www.store.leasefoundation.org/Products/2016MKST.pdf (Accessed: November 2017).

Gan, S., Zhang, Z., Zhou, Y., \& Shi, J. (2015). Joint optimization of maintenance, buffer, and spare parts for a production system. Applied Mathematical Modelling, 39(19), 6032-6042. https:/ / doi.org/10.1016/j.apm.2015.01.035

Gharbi, A., Kenne, J.-P., \& Beit, M. (2007). Optimal safety stocks and preventive maintenance periods in unreliable manufacturing systems. International Journal of Production Economics, 107(2), 422-434.

https://doi.org/10.1016/j.ijpe.2006.09.018

Jaturonnatee, J., Murthy, D.N.P., \& Boondiskulchok, R. (2006). Optimal preventive maintenance of leased equipment with corrective minimal repairs. European Journal of Operational Research, 174(1), 201-215.

https://doi.org/10.1016/j.ejor.2005.01.049

Kelly, C., Khayum, M., \& Price, C. (2013). Equipment lease financing: the role of community banks. Proceedings of Community Banking in the 21st Century Conference 2013 (CSBS 2013). St. Louis, Missouri. Available at: https://www.stlouisfed.org/ /media/Files/PDFs/Banking/CBRC2013/Community Banking Conference Kelly Khayum and Price.pdf?la=en (Accessed: January 2018).

Li, W., \& Zuo, M.J. (2007). Joint optimization of inventory control and maintenance policy. Proceedings of Annual Reliability and Maintainability Symposium 2007 (RAMS). Orlando, Florida. Available at: http://ieexplore.ieee.org/stamp/stamp.jsp?tp=\&arnumber=4126370 (Accessed: December 2017). 
Murino, T., Romano, E., \& Zoppoli, P. (2009). Maintenance policies and buffer sizing: An optimization model. WSEAS Transactions on Business and Economics, 6(1), 21-30. http://www.wseas.us/e-library/transactions/economics/2009/28-415.pdf

Murthy, D.N.P., \& Pongpech, J. (2008). Maintenance of leased equipment. In Kobbacy, K.A H., \& Murthy, D.N.P. (Eds.), Complex system maintenance handbook (394-415). London: Springer-Verlag London. https://doi.org/10.1007/978-1-84800-011-7_16

Nahas, N. (2017). Buffer allocation and preventive maintenance optimization in unreliable production lines. Journal of Intelligent Manufacturing, 28(1), 85-93. https://doi.org/10.1007/s10845-014-0963-y

Nisbet, A., \& Ward, A. (2001). Radiotherapy equipment-purchase or lease?. The British Journal of Radiology, 74(884), 735-744. https://doi.org/10.1259/bjr.74.884.740735

Niyamosoth, T. (2014). Studies on inventory models with machine breakdowns. Unpublished doctoral dissertation, University of Chinese Academy of Sciences, Beijing.

Niyamosoth, T., \& Pongpech, J. (2007). Optimal multiple-periodic preventive maintenance policy for leased equipment. Proceedings of International DSI/Asia and Pacific DSI 2007. Bangkok, Thailand. Available at: http://gebrc.nccu.edu.tw/proceedings/APDSI/2007/papers/Final_29.pdf (Accessed: January 2018).

Pham, H., \& Wang, H. (1996). Imperfect maintenance. European Journal of Operational Research, 94(3), 425-438. https://doi.org/10.1016/S0377-2217(96)00099-9

Pongpech, J., \& Murthy, D.N.P. (2006). Optimal periodic preventive maintenance policy for leased equipment. Reliability Engineering \& System Safety, 91(7), 772-777. https://doi.org/10.1016/j.ress.2005.07.005

Pongpech, J., Murthy, D.N.P., \& Boondiskulchock, R. (2006). Maintenance strategies for used equipment under lease. Journal of Quality in Maintenance Engineering, 12(1), 52-67. https://doi.org/10.1108/13552510610654538

Zhou, B., \& Liu, Z. (2016). Optimizing preventive maintenance: a deteriorating system with buffers. Industrial Management \& Data System, 116(8), 1719-1740. https://doi.org/10.1108/IMDS-01-2016-0026

Zhou, X., Li, Y., Xi, L., \& Lee, J. (2015). Multi-phase preventive maintenance policy for leased equipment. International Journal of Production Research, 53(15), 4528-4537. https://doi.org/10.1080/00207543.2014.990116

Journal of Industrial Engineering and Management, 2018 (www.jiem.org)

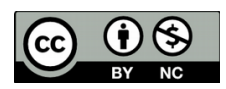

Article's contents are provided on an Attribution-Non Commercial 4.0 Creative commons International License. Readers are allowed to copy, distribute and communicate article's contents, provided the author's and Journal of Industrial Engineering and Management's names are included. It must not be used for commercial purposes. To see the complete license contents, please visit https://creativecommons.org/licenses/by-nc/4.0/. 